\title{
Advance directives in cancer patients
}

\begin{abstract}
Introduction: Advance Directives (AD) represent the patient's expression about end-oflife care. Patients who have AD and discuss quality of death, take part in decision making about their care more often and have their choices respected. The diagnosis of cancer seems to favor the establishment of DA and discussions about end of life care.

Methods: It is a systematic literature review that aims to assess the prevalence of $\mathrm{AD}$ among cancer patients and the attitude of patients and physicians across $\mathrm{AD}$ in the context of oncology. 10 articles were selected for the analysis in the data source of PubMed and BIREME / LILACS.

Results: The prevalence of AD among cancer patients ranged from $88 \%$ among Americans at $55 \%$ in Canadian. In Europe was low, only 5\% cancer patients in one study. Age, level of education, high income, worse Performace Status (PS), prolonged treatment and follow up with a team of palliative care was positive factors related to the development of Advance Directives by cancer patients. The oncologist had the lowest representation among health professionals and family in the formulation process of Advance Directives. Conclusion: The discussion on $\mathrm{AD}$ involves, among other things, special attention to the models of physician-patient relationship, particularly the right of choice of patient and respect for their best interest.
\end{abstract}

Keywords: advance directives, cancer patients, attitudes, prevalence
Volume 2 Issue 2 - 2018

\author{
Eni Devay de Freitas, ' Anderson de Almeida \\ Rocha, ${ }^{2}$ Rui Nunes ${ }^{3}$ \\ 'Faculty of Medicine, State University of Bahia, Brazil \\ ${ }^{2}$ Federal University of Juiz de Fora, Brazil \\ ${ }^{3}$ Faculty of Medicine, University of Porto, Portugal
}

Correspondence: Eni Devay de Freitas, Faculty of Medicine of the State University of Bahia, Rua Silveira Martins Martins, 2555-Cabula, Salvador-BA, ZIP Code 4I I 50-000, Brazil, Tel +55(7I) 98I95- 4065, Fax +55(7I)3II7-2290,

Email enifreitas@hotmail.com

Received: February 07, 2018 | Published: March 12, 2018

\section{Introduction}

Advance Directives (AD) represents the patient's expression about end-of-life care.Indeed, it is accepted that patients may refuse or set limits on treatment and medical interventions in end-of-life care planning, ${ }_{1}^{1}$ or determine a legal representative who decides for them. ${ }^{2}$ These wishes can be expressed in several documents among them Living Will (LW), ${ }^{3}$ adopted since the 70 's in the USA as a legal instrument known as "Testamento Vital" in Portuguese speaking countries. In Brazil, advance directives has been regulated in 2012 by the Federal Council of Medicine through the Resolution 1,995/2012, ${ }^{5}$ allowing the registration of the patients choicesin the medical record as a tool to promote the patient's right to self-determination.

Talking about Advance Directives in plural democratic societies implies considering specific social, cultural and economic factors that affect the behavior of patients, family and doctors, inserted in a state of law based on human dignity and self-determination of the individual. In general, discussions about $\mathrm{AD}$ and end-of-life care can be hampered by any of the actors involved in the process. These difficulties reflect emerging issues of bioethics involving the human being's ability to intervene on life and death, changing the concept of death in Western societies, as well as the need for new models of medical-professional relationship taking into account the right and dignity of the patients. Biotechnological advances have brought human beings' ability to manipulate life, interfere with health and disease conditions, and prolong the time of death. Death moves from a natural condition to become an undesirable event, maximally preventable, that people cannot talk and want to drive out of their lives, in contemporary societies. ${ }^{6}$

Even in a not very favorable scenario, studies show that patients who have $\mathrm{AD}$ and discuss end-of-life care and quality of death participate more in decision making and are more likely to receive care according to their choices. These patients also tend to have fewer ICU admissions, fewer measures of unnecessary life extension interventions, and increased frequency of hospice care and death at home. ${ }^{7-10}$ Cancer represents more than 100 different types of diseases, according to $\mathrm{WHO},{ }^{11}$ with different prognoses. However, the diagnosis of cancer, in itself, is involved in a very big stigma of aggressive and fatal disease. This "closeness" to death, caused by the disease, probably explains at least partially the results of the studies, demonstrating that advanced age and diagnosis of cancer are factors associated with a greater filling of $\mathrm{AD}$ and discussions about end-oflife care. ${ }^{12}$ Cancer patient who receive multidisciplinary care since the diagnosis of cancer, seeking a better quality of life, more often discuss the modalities of care and treatment and establish their AD. ${ }^{13}$

\section{Objective}

The aim of this study is to review the literature on the use of Advance Directives in cancer patients, assessing issues such as the prevalence of $\mathrm{AD}$ among these patients before and after the diagnosis of cancer, and the attitude of patients and physicians to DA.

\section{Methods}

This is a systematic review of the literature. A search was performed on the data sources of PUBMED and BIREME / LILACS using the descriptors: advance directives and cancer patients and attitudes and prevalence. The research resulted in a total of 22 articles in the sources of BIREME and 24 articles in research by PUBMED. The selection criteria for inclusion of the articles in this review were original quantitative studies, written in the English language, discussing the topic Advance Directives (AD) in the cancer patient, with a descriptive or analytical methodology on prevalence of $\mathrm{AD}$, attitudes of the physician or patient related AD and end-of-life care.

After reading the title and abstract of 46 articles, 34 articles were excluded from the data source LILACS/ BIREME and 19 PUBMED articles. Subjects whose sample was not cancer patients, who did not address $\mathrm{AD}$ in oncology patients or whose attitudes assessment 
referred to non-medical professionals and those in Asian populations were excluded. 04 articles were selected in the sources of BIREME / LILACS and 05 articles in PUBMED; 04 articles were repeated in the two different sources. The study included five articles, randomly found in literature reference readings that meet the inclusion criteria. At the end, a total of 10 articles were selected for analysis considering the specific information of each article (Figure 1). The quantitative data on the prevalence of $\mathrm{AD}$ in cancer patients before and after the diagnosis of cancer, patient's attitudes regarding the diagnosis of cancer in relation to $\mathrm{AD}$ and end-of-life care and the attitudes of medical oncologists to define end-of-life care and discuss AD with their patients were analyzed for the description in this study.

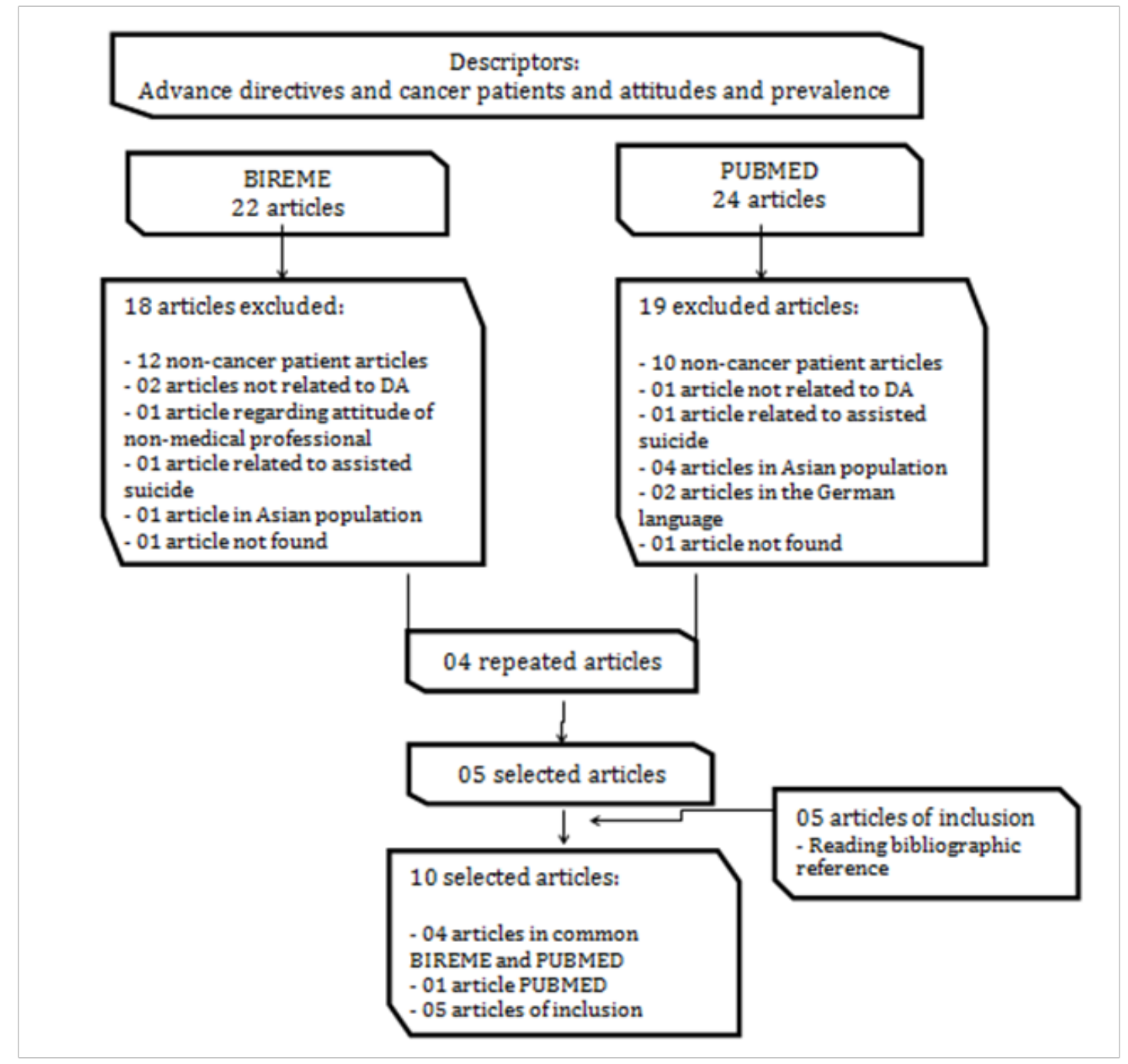

Figure I Flowchart of article selection.

\section{Results}

Studies in cancer patients over the past decade in the United States show that around $70 \%$ of patients knew or had information about Advance Directives and only $35 \%$ to $49 \%{ }^{14}$ had completed DA documents before the diagnosis of cancer. In Canada, studies show that $45 \%{ }^{15}$ to $55 \%$ of patients had AD completed. ${ }^{16}$ After the diagnosis of cancer, the prevalence of $\mathrm{AD}$ among patients increased to $88 \%$ in American studies ${ }^{17}$ and remained at $45 \%$ to $55 \%$ in the Canadian studies. ${ }^{15,16}$ In Europe, the prevalence of AD was $23 \%$ among cancer patients in a German study ${ }^{18}$ and only $5 \%$ in cancer patients in Vienna, Austria. ${ }^{19}$ In the German study ${ }^{18}$ although only $23 \%$ of the patients had $\mathrm{AD}, 62 \%$ of them showed desires to perform their $\mathrm{AD}$, while $85 \%$ of cancer patients hospitalized in the city of Vienna did not wish to have $\mathrm{AD} .^{19}$

Retrospective data of patients with advanced cancer in US cities, between the years 2002-2008, showed that $88 \%$ (413 patients) had $\mathrm{AD}$ and care settings at the end-of-life. Documents completed by the patients were the Living Will (LW) or Durable Power of Attorney (DPA) in $53 \%$ (with $33 \%$ of patients had both) and do not resuscitate orders (DNR) in $41 \% .{ }^{17}$ In the state of Maryland, of 100 patients with advanced stage cancer, $49 \%$ had LW or DPA. ${ }^{20}$ In the MD Anderson Cancer Center in Houston, of the 110 women diagnosed 
with gynecological cancer, 49\% (54 patients) had AD, but only $37 \%$ of them had copies of these documents in hand if necessary. ${ }^{14}$ In this same study, $73 \%$ of patients who had cancer recurrence had more access to information on $\mathrm{AD}$, but this condition did not increase the proportion of AD filling, remaining at $48 \% .{ }^{14}$ In Baltimore, ${ }^{20}$ United States, 93 patients with end stage cancer were asked about their own perception of prognosis and desires for end-of-life care. Although all patients were informed about the prognosis and terminal stage of disease, provided by their physicians, only $43 \%$ of them confirmed this understanding of terminality. $25 \%$ of patients had talked with their oncologist about their care wishes at the end of life, but most patients $(56 \%)$ did not want to discuss this topic with their doctors. Do-not-resuscitate Orders (DNR) were best accepted in patients with an expected 1-month life expectancy (61.7\%), allowing for a natural course to occur". Allow natural death - AND" $(47.8 \%) .{ }^{20}$ Garrido et al. ${ }^{17}$ also demonstrated that the presence of Do-not-resuscitate Orders was associated with significantly better quality of life in the weeks before death, which was not observed for those who had only LW / DPA.

In Canada, a study of 193 cancer patients treated in the Princess Margaret Cancer Center, Toronto, from 2011 to 2012, showed that $55 \%$ of them had done an $\mathrm{AD}$. AD documents were a $\mathrm{LW}$ in $33 \%$, $49 \%$ DPA and $18 \%$ DNR. Of the 99 patients who had AD, $53 \%$ had made it before the diagnosis of cancer, $24 \%$ up to 1 year of cancer diagnosis, $10 \%$ between $1-2$ years of diagnosis of cancer and $10 \%$ after recurrence or progression of cancer. ${ }^{16}$ The study also showed that both the family and the lawyer were references in assisting the filling of anDA: $47 \%$ of the patients had family assistance, $43 \%$ of a lawyer; $5 \%$ of the palliative care team; only $1 \%$ of the oncologist. $25 \%$ of the patients had no help. Regarding the expression of wishes of care at end-of-life, $66 \%$ of patients had talked with the family; $9 \%$, with lawyer; $6 \%$, with the palliative care team; $3 \%$ with the oncologist; $2 \%$ with the family physician and $31 \%$ had not discussed their endof-life care wishes with anyone. ${ }^{16}$ Age,${ }^{21}$ level of education and high income, worse Performace Status (PS), ${ }^{14,16,18}$ prolonged treatment and follow up with a team of palliative care, were positive factors related to the development of Advance Directives by cancer patients. The oncologist had the lowest representation among health professionals and family in the formulation process of Advance Directives.

Palliative care and discussion of care in end-of-life had a statistically significant association for AD fill after cancer diagnosis. Patients who developed their $\mathrm{AD}$ after cancer diagnosis were more likely to be followed up by a palliative care team ( $82 \%$ vs. $63 \%$; $\mathrm{p}<0.0001) .{ }^{16}$ Patients who were followed up with palliative care discussed further end-of-life care. Factors demonstrated as potential barriers to $\mathrm{AD}$ completion by the patients were younger age, low educational level, and a high level of anxiety related to death. ${ }^{14} \mathrm{~A}$ study of cancer patients hospitalized in Vienna found that $85 \%$ of them did not express desire to have $\mathrm{AD}$ and the reasons were: $22 \%$ had complete trust in their doctors leaving the decision to them; $15 \%$ considered to have no importance at that time; $8 \%$ considered that $\mathrm{AD}$ could lead the doctor to make the wrong decisions and $7 \%$ said they did not have the information needed to perform an $\mathrm{AD} .{ }^{19}$ In the German study, most patients with or without AD agreed that $\mathrm{AD}$ facilitated medical decision-making and reduced the burden on relatives. However $36 \%$ believed that AD could be of little use, since people define their $\mathrm{AD}$ before they become ill and when they are ill the choices could change. ${ }^{18}$
A study at a cancer center, in New York, evaluated the different perceptions and beliefs into 03 ethnic/racial groups $(21 \%$ of black, $20 \%$ of Hispanic and $59 \%$ of non-minority) of patients diagnosed with lung cancer. Of 335 patients evaluated, $80 \%$ expressed the desire that communication about their disease occur together with family. The group of Hispanic patients had a belief that LW, once performed, could not be altered and its realization would depend on the participation of a lawyer. Black patients had a significantly larger belief in relation to the other two groups that people with LW would not receive cancer treatment and a belief 2.5 times greater that life-sustaining treatments had to be maintained for religious reasons. Black and Hispanic patients attributed to hospices, the places of care for people who were close to death. ${ }^{22}$

Two studies evaluated the attitudes of oncologist physicians in discussing end-of-life care and AD. Previous studies have demonstrated that female physicians introduced early and more frequently the discussions with patients and family on psychosocial and biomedical aspects related to end-of-life care. Crosby et al. ${ }^{21}$ evaluated the issue of physician gender interfering with communication and approach to preventive care practices such as discussions at the end of life. The study was conducted at the MD Anderson Cancer Center, Texas, United States, from 2011 to 2013, assessed the frequency of records of Do-not-resuscitate Orders in cancer patients and the duration of the first registration during the days of hospitalization, from the followup of female and male physicians. The results showed that female physicians had an earlier record, in the first days of hospitalization, of Do-not-resuscitate Orders compared to male physicians. When it came to female patients accompanied by female doctors, this registry was even earlier to hospitalization.

The study by Kierner et al. ${ }^{23}$ used a questionnaire sent to 758 oncologists in Austria, evaluating the frequency of prognostic information given to the patient, referral of cancer patients to palliative care or hospice services and discussion of $\mathrm{AD}$ with their patients. Palliative care or hospice care were offered for only $8,6 \%$ and $2,6 \%$ of patients, respectively, by oncologists. The justifications were: the non-availability of palliative care services for $25 \%$ of physicians and the belief that these referrals would negatively impact the hopes of patients for $75 \%$ of physicians. $66 \%$ of oncologists talked with their patients about the malignancy characteristic of the disease and the cancer prognosis but only $28 \%$ of the patients received information about AD from their oncologists. Most physicians (66\%) did not discuss $\mathrm{AD}$ with their patients because they believed it would bring no benefit to the patient, and $30 \%$ of them still feared to destroy the hope of patients. Depending on the timing of the disease, only $66 \%$ of oncologists would inform their patients about prognosis soon after diagnosis. $98 \%$ of oncologists considered Performance Status (KPS below 50), an important factor to communicate bad news about the prognosis of the disease. ${ }^{23}$

\section{Discussion}

Articles of this study show that the prevalence of AD among cancer patients was very varied between countries: the Americans had a higher prevalence of AD before and after the diagnosis of cancer, reaching up to $88 \%{ }^{17}$ from patients after diagnosis, followed by Ccnadians. ${ }^{16}$ The two European studies included in the analysis had a low prevalence of $\mathrm{AD}$, especially the Austrian study where only $5 \%$ of cancer patients had AD completed. ${ }^{19}$ Articles are mostly hospital-based, not population, but reflect the different social, cultural 
and economic aspects of local influencing. In the United States, the prevalence of $\mathrm{AD}$ among elderly non-cancer patients, for example, is around $70 \%,{ }^{7}$ equivalent to the data for cancer patients found in the studies. The American data reflect a socio-cultural reality of a society that since the 1970s has as a standard of medical assistance the indication of resuscitation of all patients in CRP (Cardiac Arrest), except for those who have an Advance Directive or order do not resuscitate "DNR". ${ }^{24}$ Since the $70 \mathrm{~s}$, the Americans instituted AD instruments such as the Living will and later with advances in local legislation in the 90s, the Patient Self Determination Act (PSDA) ${ }^{25}$ which establishes the obligation of treatment facilities to promote education of professionals and patients about Advance Directives and the provision of $\mathrm{AD}$ documents, optional the fulfillment of patients.

Articles of this study made references to some documents used as AD, among them: the Living Will (LW), Durable Power of Attorney (DPA) and the records of do not resuscitate orders "DNR" and death in natural course "AND". An important aspect that constitutes a barrier to ensure the choices of patients is unavailability of $\mathrm{AD}$ documentation addressed in one of the studies. ${ }^{15}$ In Portugal, the public discussion on AD culminated in 2012 with the approval of the Law 25/2012 that also created the National Registry of the Living Will, called RENTEV, allowing real-time access to the patients' AD within the healthcare systemintranet. ${ }^{26}$

Articles of this study demonstrated that advanced age,${ }^{21}$ education level and high income ${ }^{14,16,18}$ worsen Performance Status (PS) and also originated aprolongation ${ }^{18,19}$ of the duration of treatment and follow up by a team of palliative care were factors that were positively related to the filling of $\mathrm{AD}$ in cancer patients. Some of these findings are also found in the literature, in non-oncological and oncological patients..$^{14,27,28}$ On the other hand, the lack of accessibility, information and understanding related to social conditions constituted obstacles to the performance of $\mathrm{AD}$ by the patients ${ }^{14,19}$ as in the study by Jonnalagadda, ${ }^{22}$ demonstrating the belief of American racial minorities about $\mathrm{AD}$ as tool that does not guarantee adequate treatment against cancer. Religion was a valued aspect and also highlighted in the study toward healing beliefs and miracles attributed to God as barriers to establishing their wills or restriction. ${ }^{22}$

Only one article ${ }^{16}$ demonstrated an increase in the proportion of AD after the patients were diagnosed with cancer. This same study showed that patients talk mainly with their families about their care wishes at the end of life, and only a very small percentage, around $6 \%$ talk to the palliative care team and only $3 \%$ with their oncologists. Follow-up with a palliative care team was a factor associated with increased AD, as well as a discussion about the care patients would like to receive at the end of life. ${ }^{16}$ In the literature, intervention studies have shown that cancer patients, accompanied by an interdisciplinary team of palliative care, discuss and express more, significantly, their preferences and choices in $\mathrm{AD} .{ }^{13,29}$ An American study in lung cancer patients showed that $44 \%$ of patients followed up by an interdisciplinary Palliative Care team had $\mathrm{AD}$, whereas only $9 \%$ of unaccompanied patients had AD $(\mathrm{p}<0.001)$. The American (ASCO) and European (ESMO) Societies of Medical Oncologists advocate comprehensive medical care for oncological patients, involving not only the management of signs and symptoms of the disease but also the emotional and human aspects, and since 2012, the expression of the preferences and desires of patient care as early as possible after the diagnosis of cancer. The ESMO (European Society of Medical Oncology) ${ }^{30}$ highlights the importance of an advanced care planning (ACP) involving medical communication, listening, understanding and expression of patients about how they want to be treated when they were unable to decide. Or during treatment, the continuation of treatment, and intervention measures for symptom relief and control, nutrition therapy, sedation and assisted suicide, allowed in some European countries. The ASCO (American Society of Clinical Oncology) ${ }^{31}$ focuses its guidelines on cancer patients with metastatic disease and survival between 6 and 24 months, establishing a care plan where the palliative care team can be integrated early, ideally in the first 8 weeks of diagnosis, and aspects of treatment, prognosis, and patient care preferences are discussed, filling in their AD. Since palliative care (PC) should be offered by a multidisciplinary and interdisciplinary team that includes clinical oncologist and / or palliative doctor at the center of attention. ${ }^{31}$

The two studies ${ }^{21,23}$ evaluating the attitude of medical oncologists with respect of an $\mathrm{AD}$ approach in cancer patients suggest that doctors themselves represent a barrier in this discussion, postponing to later stages of the disease. The literature, however, shows that talking about cancer prognosis with cancer patients allows them a better understanding and more conscious choice ${ }^{27}$ without adding suffering or stress, ${ }^{13}$ enabling greater effectiveness of their choices ${ }^{27}$ and avoiding futile treatments, ${ }^{32}$ without compromising the quality of the doctor-patient relationship..$^{10}$

\section{Conclusion}

Discuss an $\mathrm{AD}$ with a patient means tailor medical-patient relationship models to the principles of bioethics, as regards the right to patient choices and respect for their dignity, and discuss of emerging issues related to technological scientific advancement and its effects on medical practice, in the limits of intervention on life and death by human beings. Postpone choices, by any of the actors, leaving decisions about care at the end of life for a time of greater proximity of death, can generate situations of uncertainty, additional suffering and conflicts between patient, family and physician. In some situations, the expression of the patient's desire not to artificially prolong life and suffering may not be in agreement with that of the family, who understands his sick relative as a vulnerable and still feeds expectations of prolonging the survival to the current technological limits. The doctor finally have to weigh the ethical, human and technical dimensions in decision-making involving care at end-of-life, preventing the principle of beneficence to be confused with paternalism, avoiding interventions that are characterized as excessive and unnecessary, taking into account the desire of the patient or his legal representative, if so determined.

These discussions should be encouraged in society and among health professionals, especially among physicians. There are beliefs and uncertainties which still need to be better clarified and deepened beyond the taboo of death in the training and medical practice and represent barriers to physicians, hindering the exercise of autonomy and respect for the patient's dignity.

\section{Acknowledgements}

None.

\section{Conflict of interest}

The author declares no conflict of interest.

\section{References}

1. World Health Organization. Ageing and health technical report vol 5: a glossary ofters for health care and services for older people. Geneva: WHO; 2004. 
2. Silveira MJ, Kim SY, Langa KM. Advanced directives and outcomes of surrogate decision making before death. $N$ Eng $J$ Med. 2010;362(13):1211-1218.

3. Kunter L. Due Process of Euthanasia: The Living Will. Indiana Law. 2017;44(4):540-554.

4. Pereira AD. Living Will and health care proxy- the Portuguese legal situation. Med Law. 2013;32(4):497-502.

5. http://www.portalmedico.org.br/resolucoes/CFM/2012/1995_2012.pdf

6. Ariès P. A historia da morte no Ocidente. Rio de Janeiro: Francisco Alves; 1977.

7. Teno JM, Gruneir A, Schwartz Z, et al. Association between advance directives and quality of end-of-life care: a national study. J Am Geriatr Soc. 2007;55(2):189-194.

8. Finlay E, Shreve S, Casarett D. Nationwide veterans affairs quality measure for cancer: the family assessment for treatment end of life. $J$ Clin Oncol. 2008;26(23):3838-3844.

9. Houben $\mathrm{CH}$, Spruit MA, Groenen MT, et al. Efficacy of advance care planning: a systematic review and meta-analysis. J Am Med Dir Assoc. 2014;15(7):477-489.

10. Enzinger AC, Zhang B, Schrag D, et al. Outcomes of Prognostic Disclosure: Associations With Prognostic Understanding, Distress, and Relationship With Physician Among Patients With Advanced Cancer. $J$ Clin Oncol. 2015;33(32):3809-3816.

11. http://www.who.int/features/factfiles/cancer/facts/en/index7.html

12. Lovell A, Yates P. Advance care planning in palliative care: a systematic literature review of the contextual factors influencing its uptake 20082012. Palliat Med. 2014;28(8):1026-1035.

13. Ferral B, Sun V, Hurna A, et al. Interdisciplinar palliative care for patients with lung cancer. J Sympom Manage. 2015;50(6):758-767.

14. Brown AJ, Shen M J, Alaina DU, et al. Room for improvement: An examination of advance care planning documentation among gynecologic oncology patients. Gynecol Oncol. 2016;142(3):525-530.

15. Caissie A, Kevork N, Hannon BL, et al. Timing of code status documentation and end-of-life outcomes in patients admitted to an oncology ward. Support Care Cancer. 2014;22(2):375-381.

16. McDonald JC, Manoir JM, Kevork N, et al. Advance directives in patients with advanced cancer receiving active treatment: attitudes, prevalence, and barriers. Support Care Cancer. 2017;25(2):523-531.

17. Garrido MM, Balboni TA, Maciejewski PK, et al. Quality of Life and Cost of Care at the End of Life: The Role of Advance Directives. J Pain Symptom Manage. 2015;49(5):828-835.

18. Oorschot B, Schuler M, Simon A, et al. Advance directives: prevalence and attitudes of cancer patients receiving radiotherapy. Support Care Cancer. 2012;20(11):2729-2736.
19. Kierner KA, Hladschik-Kermer B, Gartner V, et al. Attitudes of patients with malignancies towards completion of advance directives. Support Care Cancer. 2010;18(3):367-372.

20. Miljkovic MD, Emuron D, RhodesL, et al. Allow natural death versus do not resuscitate: What do patients with advanced cancer choose? J Palliat Med. 2015;18(5):457-460.

21. Crosby MA, Cheng L, DeJesus AY, et al. Provider and Patient Gender Influence on Timing of Do-Not-Resuscitate Orders in Hospitalized Patients with Cancer. J Palliat Med. 2016;19(7):728-733.

22. Jonnalagadda S, Lin JJ, Nelson JE, et al. Racial and ethnic differences in beliefs about lung cancer care. Chest. 2012;142(5):1251-1258.

23. Kierner KA, Gartner V, Bartsch R, et al. Attitudes towards palliative care in primary metastatic cancer: a survey among oncologists. Wien Klin Wochenschr. 2010;122(1-2):45-49.

24. Loertscher L, Reed DA, Bannon MP, et al. Cardiopulmonary resuscitation and do-not-resuscitate orders: a guide for clinicians. Am J Med. 2010;123(1):4-9.

25. Bogardus ST, Bradley EH, Williams CS, et al. Goals for the care of frail older adults: do Caregivers and clinicians agree? $\mathrm{Am} \mathrm{J} \mathrm{Med.}$ 2001;110(2):97-102.

26. Nunes R. Diretivas antecipadas de vontade. Rev bioét. 2014;22(2):241251.

27. Temel JS, Greer JA, Admane S, et al. Longitudinal perceptions of prognosis and goals of therapy in patients with metastatic non-smallcell lung cancer: Results of a randomized study of early palliative care. $J$ Clin Oncol. 2011;29(17):2319-2326.

28. Mack W, Weeks JC, Wright AA, et al. End-of-life discussions, goal attainment, and distress at the end of life: predictors and outcomes of receipt of care consistent with preferences. $J$ Clin Oncol. 2010;28(7):1203-1208.

29. Zimmermann C, Swami N, Krzyzanowska M, et al. Early palliative care for patients with advanced cancer: A cluster-randomised controlled trial. Lancet. 2014;383():1721-1730.

30. Schrijvers D, Cherny NI, ESMO Guidelines Working Group. ESMO Clinical Practice Guidelines on palliative care: advanced care planning. Ann Oncol. 2014; 25(Supplement 3):iii138-142.

31. Ferrell BR, TemelJS, Temin S, et al. Integration of Palliative Care Into Standard Oncology Care: American Society of Clinical Oncology Clinical Practice Guideline Update. J Oncol Pract. 2016;13(2):119-121.

32. Lundquist G, Rasmussen BH, Axelsson B. Information of imminent death or not. Does it make a difference? J Clin Oncol. 2011;29(29):39273931. 